\title{
Occurrence of Multi-Drug Resistant Listeria species in Faecal Samples of Poultry Chickens in Rural Farms in Lagos State, Nigeria
}

\author{
Emelda E. Chukwu1 ${ }^{*}$, Veronica N. Ibeh², Olabisi F. Davies-Bolorunduro ${ }^{3}$ \\ ${ }^{1}$ Center for Infectious Diseases' Research, Microbiology Department, Nigerian Institute of Medical Research, Yaba, Lagos State, Nigeria \\ ${ }^{2}$ National Agency for Food and Drug Administration and Control, Lagos State, Nigeria \\ ${ }^{3}$ Center for Tuberculosis Research, Microbiology Department, Nigerian Institute of Medical Research, Yaba, Lagos State, Nigeria \\ Email: *emeldachukwu123@gmail.com
}

How to cite this paper: Chukwu, E.E., Ibeh, V.N. and Davies-Bolorunduro, O.F. (2021) Occurrence of Multi-Drug Resistant Listeria species in Faecal Samples of Poultry Chickens in Rural Farms in Lagos State, Nigeria. Advances in Infectious Diseases, 11, 49-59.

https://doi.org/10.4236/aid.2021.111007

Received: January 13, 2021

Accepted: March 8, 2021

Published: March 11, 2021

Copyright $\odot 2021$ by author(s) and Scientific Research Publishing Inc. This work is licensed under the Creative Commons Attribution International License (CC BY 4.0).

http://creativecommons.org/licenses/by/4.0/ (c) (i) Open Access

\begin{abstract}
Background: Listeriosis is a common zoonotic disease caused by a foodborne pathogen, Listeria monocytogenes. Poultry meat and products have been established as vehicles of transmission of pathogenic Listeria strains to humans. This study evaluates the occurrence of Listeria species in faeces of poultry chicken in Lagos. Methods: One hundred and fourteen pooled fresh faecal samples from cage-reared broiler chickens were collected from 12 farms in three rural areas in Lagos State from May to August 2019. All samples were analysed for Listeria species detection according to ISO11290-1 standard and confirmed using PCR assay. Susceptibility testing was performed using the Kirby-Bauer disc diffusion technique. Results: Twenty-eight (24.6\%) Listeria species were detected from 114 faecal samples. The isolated Listeria species were L. monocytogenes 8 (7.0\%), L. ivanovii 9 (7.9\%), L. grayi 7 (6.1\%) and $L$. innocua 4 (3.5\%). There was no significant difference in the frequency of occurrence of Listeria species across the different locations $\left(\mathrm{X}^{2}=4.98, \mathrm{p}=0.08\right)$. The listeria species were susceptible to Augmentin (96.4\%), vancomycin (85.7\%) and co-trimoxazole (82.1\%), but resistant to ceftazidime (100\%), tetracycline $(75.0 \%)$ and ciprofloxacin (71.4\%). Conclusion: This study reveals high occurrence of multi-drug resistant Listeria species in faecal samples of poultry chickens in Lagos state which may be an important vector in the contamination of the environment and transmission of antibiotic resistant $\mathrm{Lis}$ teria species to consumers.
\end{abstract}

\section{Keywords}

Listeriosis, Listeria monocytogenes, Multi-Drug Resistance, Poultry Farms, Zoonotic Disease, Chickens 


\section{Introduction}

Listeria monocytogenes infection is associated with consumption of food contaminated with animal faeces and has been reported as a common inhabitant of the digestive tracts of animals including cattle, poultry and pigs [1]. Typical sources of ingestion by humans are raw foods of animal and soil origin, such as raw milk and dairy products, fresh meat, fruit, vegetables and seafood as well as ready-to-eat (RTE) foods [1] [2] [3]. Reports of outbreaks have also followed ingestion of undercooked meat, poultry as well as coleslaw where it was first recognized as a food-borne zoonosis.

In Nigeria, poultry meat and products have been fingered as a potential vehicle of transmission of pathogenic strains of Listeria to humans [4] [5] [6]. Early studies on Listeria in Nigeria concentrated on the occurrence of the organism in humans while studies on animals commenced in the late eighties. Occurrence of the L. monocytogenes has been reported in farm animals in Nigeria. Ishola and colleagues [5] reported high level (91.8\%) of contamination of chicken flocks and meat with L. monocytogenes in Oyo State, south-western Nigeria. An outbreak of listeriosis was reported in a herd of cattle in the South-Western city of Ibadan [7]. The organism was isolated in pure culture and the infected animals were associated with still birth, abortion and nervous signs before death. Chukwu et al. [8] reported the first case of L. monocytogenes infection in an African buffalo (Syncerus caffer) that presented with septicaemia and abortion. Although the animal recovered after treatment, the authors emphasized the need for further investigation of listeriosis in wildlife. An early survey conducted by Oni et al. [9] to determine the prevalence of antibody to Listeria serotypes in 1190 serum samples from various animal sources in Kano and Kaduna States revealed that $L$. monocytogenes infection is widespread in domestic animals in Nigeria.

Listeria species have been isolated from all stages of poultry production and processing and emerging studies suggest that poultry birds might be an important source of contamination of production processes which could lead to transmission of infection to consumers [10]. This study therefore evaluates the occurrence of Listeria species in faeces of poultry chicken in selected rural farms in Lagos State, highlighting their antibiogram for further insight.

\section{Methodology}

Study Design/Sampling: The study was a cross-sectional survey of poultry farms in rural areas in Lagos State. Three local government areas (Ikorodu, Epe and Ojo) were purposively selected out of the four rural local government areas (LGAs) in the state due to their accessibility. A list of all registered poultry farms in each study location was constituted and used to randomly select four farms per LGA using table of random numbers. Fresh faecal samples were collected from cage-reared broiler chickens in 12 farms (4 farms per LGA) from May to August 2019. The faecal samples were picked up early in the morning from each 
site and pooled according to the cages ( 2 to 5 samples collected from different areas representative of the cage). The samples were collected into sterile universal bottles and kept at refrigerator temperature until they reached the laboratory for analysis as suggested by Hitchins et al. [11]. Microbiological and molecular work was carried out at the Microbiology laboratory of the Nigerian Institute of Medical Research.

\section{Faecal culture:}

This was done according to a modified version of the guideline stipulated by standard ISO 11290-1. Faecal samples were pre-enriched in $9 \mathrm{ml}$ of $0.1 \%$ peptone water ( 1 part to 9 parts peptone water). The homogenized faecal material in peptone water was incubated overnight at $35^{\circ} \mathrm{C}$. One $\mathrm{ml}$ of the homogenized samples was transferred into $9 \mathrm{ml}$ of Listeria enrichment broth for selective enrichment and incubated at $35^{\circ} \mathrm{C}$ for $24 \mathrm{~h}$ as recommended by Curtis et al. [12]. Plating was done using the procedures of the Centre for Disease Control by using a sterile wire loop to inoculate the broth culture onto Listeria selective medium agar base plates (Oxford formulation) and incubated at $35^{\circ} \mathrm{C}$ for 24 hours under anaerobic conditions. Typical colonies of $L$. monocytogenes were examined after 24 - 48 hours.

\section{Identification and characterization of isolates}

The Listeria isolates were presumptively identified on the basis of colonial morphology and appearance, gram staining reaction, black halo production on Listeria selective agar. They were subsequently inoculated into freshly prepared Tryptose soy agar plate and used to carry out biochemical tests. Identification and classification of the different Listeria species were done using results of the biochemical tests including catalase test, motility test, and Christie, Atkins, Munch-Petersen (CAMP) test as described by Rapeanu et al. [13], $\beta$-hemolytic activity and sugar fermentation tests (xylose, rhamnose, mannitol and methyl d-mannopyranoside), oxidase test and methyl red voges proskauer (MR-VP) tests as described by Dabrowski et al. [14]. All confirmed isolates obtained were preserved in skimmed milk and Brain heart Infusion broth containing $20 \%$ glycerol and stored at $-80^{\circ} \mathrm{C}$.

Confirmation of Listeria species by molecular analysis: Polymerase Chain Reaction

Bacteria DNA was extracted by Phenol Chloroform method [15] and the concentration of the DNA was quantified using nano drop spectrophotometer (DeNovix DS-11 Spectrophotometer, Brazil) and read at $280 \mathrm{~nm}$. The specific detection of the Listeria species was based on PCR amplification of the 16S rRNA gene using oligonucleotide primers [16]. Amplifications were carried out using a final volume of $25 \mu \mathrm{L}$ PCR super-mix comprising $12.5 \mu \mathrm{L}$ Red Taq Quick-Load 5× Master Mix with Standard Buffer (New England Biolabs, U.S.A.), $0.5 \mu \mathrm{L}$ of each primer $(10 \mu \mathrm{M}), 4.5 \mu \mathrm{L}$ of nuclease free water and $5 \mu \mathrm{L}$ of bacterial genomic DNA solution was subjected to thermocycling conditions (Eppendorf master cycler gradient, Germany). The primers were prs Forward GCTGAA GAGATTGCGAAAGAAG and Reverse CAAAGAAACCTTGGATTTGCGG. 
Cycling parameters included an initial denaturation step of $95^{\circ} \mathrm{C}$ for $5 \mathrm{~min}, 35$ cycles of a denaturation step of $95^{\circ} \mathrm{C}$ for $30 \mathrm{~s}$, a primer annealing step at $58^{\circ} \mathrm{C}$ for $30 \mathrm{sec}$, an extension step at $72^{\circ} \mathrm{C}$ for $45 \mathrm{~s}$ and final extension at $72^{\circ} \mathrm{C}$ for $5 \mathrm{~min}$. The expected amplicon length for Listeria species was $370 \mathrm{bp}$. The PCR products were separated using $1.5 \%$ agarose gel electrophoresis performed in an electrophoretic tank at 90 volts for 2.5 hours (Sigma Chemical Company), stained with $0.5 \mu \mathrm{g} / \mathrm{ml}$ ethidium bromide and photographed under UV transilluminator by using a digital camera (Kodak Digital System DC-120). A DNA ladder digest of $100 \mathrm{bp}$ was used as molecular weight marker.

\section{Antimicrobial susceptibly testing}

Antibiotic susceptibility assay to 12 commonly used antibiotics was performed using the disk diffusion method (Kirby Bauer), according to the Clinical Laboratory Standards Institute criteria [17] on Mueller-Hinton agar plates (Oxoid, UK). Inoculum suspension was prepared using sterile saline to obtain turbidity comparable to 0.5 McFarland standards and sterile cotton swab was dipped, rotated across the wall of the tube to avoid excess fluid and was evenly inoculated on Muller-Hinton agar (Oxoid, UK). The antibiotic discs were placed on Muller-Hinton agar plates. The antibiotic discs that was used in this study were penicillin $(10 \mu \mathrm{g})$, chloramphenicol $(30 \mu \mathrm{g})$, Erythromycin (15 $\mu \mathrm{g})$, ciprofloxacin (5 $\mu \mathrm{g})$, gentamicin $(10 \mu \mathrm{g})$, ofloxacin $(5 \mu \mathrm{g})$, co-trimoxazole $(25 \mu \mathrm{g})$, ceftazidime (30 $\mu \mathrm{g})$, cefotaxime $(30 \mu \mathrm{g})$, tetracycline $(30 \mu \mathrm{g})$, vancomycin $(30 \mu \mathrm{g})$ and augmentin $(30 \mu \mathrm{g})$. All the antibiotics were obtained from Oxoid laboratories (OXOID). Listeria monocytogenes (ATCC 7644) and E. coli (ATCC 10536) were used as a positive and negative control respectively. Diameters of the zones of inhibition for individual antibacterial agents were translated into susceptible, intermediate, and resistant categories, according to the clinical and laboratory standards institute criteria [17]. Multiple drug resistant microorganisms were defined as resistant to three or more antibiotic classes.

\section{Data analysis}

Descriptive statistics were employed to obtain the frequencies and distributions. Nonparametric chi-squared tests were used to compare differences between different rural areas. Data were analysed using SPSS version 26 (IBM, Chicago, IL). $\mathrm{P}$-value $<0.05$ was considered statistically significant.

\section{Results}

Out of the 114 pooled fecal samples collected from the poultry, twenty-eight (28) Listeria species were detected, giving an overall prevalence of $24.5 \%$ for listeria species. All identified Listeria species showed bands at the $370 \mathrm{bp}$ using Listeria genus specific primer (Figure 1). The isolated Listeria species were L. ivanovii 9 (7.9\%), L. monocytogenes 8 (7.0\%), L. grayi 7 (6.1\%) and L. innocua 4 (3.5\%). Epe had the highest prevalence 13/38 (34.1\%) followed by Ikorodu 10/38 (26.3\%) and Ojo 5/38 (13.1\%) Table 1. However, there was no significant difference in the frequency of occurrence of Listeria species across the locations $\left(\mathrm{X}^{2}\right.$ 
M 123456789101112131415161718192021222324252627

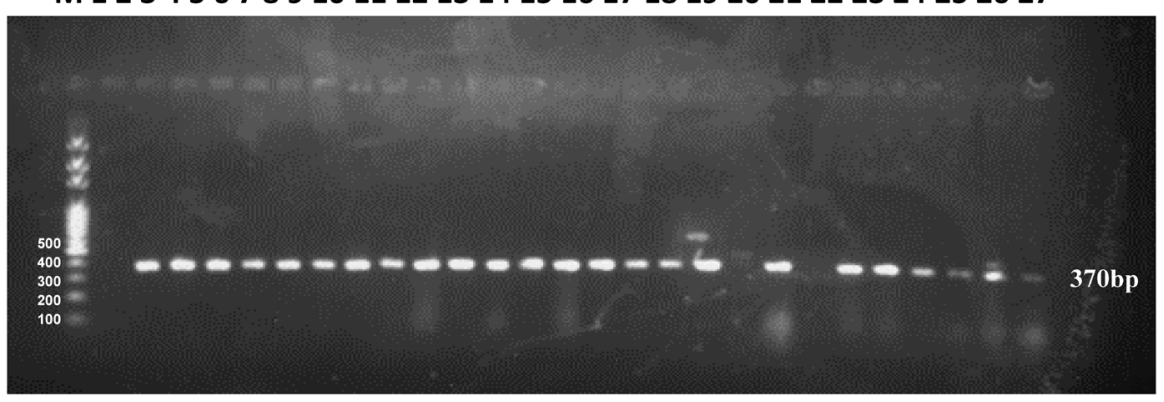

Figure 1. Agarose gel containing representative amplicon of Listeria species showing bands at $370 \mathrm{bp}$ using Listeria genus primer (PRS). Lane M, Molecular marker (100 bp DNA ladder), Lane 1 negative control, Lane 2-positive control. Lanes 3 - 27 are representative amplicon of Listeria species.

Table 1. Distribution of Listeria species among the different farms.

\begin{tabular}{|c|c|c|c|c|c|c|}
\hline $\begin{array}{l}\text { Rural } \\
\text { Farms }\end{array}$ & $\begin{array}{c}\text { No of Feacal } \\
\text { samples } \\
\mathrm{n}=114\end{array}$ & $\begin{array}{l}\text { No positive for } L \text {. } \\
\text { monocytogenes }(\%)\end{array}$ & $\begin{array}{l}\text { No positive for } \\
\text { L. ivanovii (\%) }\end{array}$ & $\begin{array}{c}\text { No positive } \\
\text { for } L \text {. grayi } \\
\text { (\%) }\end{array}$ & $\begin{array}{l}\text { No positive for } \\
\text { L. innocua (\%) }\end{array}$ & $\begin{array}{c}\text { Total No } \\
\text { positive for } \\
\text { Listeria spp (\%) }\end{array}$ \\
\hline Ikorodu & 38 & $5(13.2)$ & $3(7.9)$ & $1(2.6)$ & $1(2.6)$ & $10(26.3)$ \\
\hline Ojo & 38 & $1(2.6)$ & $1(2.6)$ & $1(2.6)$ & $2(5.3)$ & $5(13.1)$ \\
\hline Epe & 38 & $2(5.3)$ & $5(13.1)$ & $5(13.1)$ & $1(2.6)$ & $13(34.1)$ \\
\hline Total & 114 & $8(7.0 \%)$ & $9(7.9 \%)$ & $7(6.1 \%)$ & $4(3.5 \%)$ & $28(24.5)$ \\
\hline
\end{tabular}

Table 2. Antibiotic susceptibility pattern of Listeria species Isolated.

\begin{tabular}{|c|c|c|c|}
\hline ANTIBIOTICS & $\begin{array}{c}\text { SUSCEPTIBLE } \\
(\%) \\
\mathrm{N}=\mathbf{2 8}\end{array}$ & $\begin{array}{c}\text { INTERMEDIATE } \\
\text { (\%) } \\
\text { N }=28\end{array}$ & $\begin{array}{c}\text { RESISTANCE } \\
(\%) \\
\mathrm{N}=28\end{array}$ \\
\hline VANCOMYCIN & $24(85.7)$ & $0(0)$ & $4(14.3)$ \\
\hline ERYTHROMYCIN & $7(25.0)$ & $7(25,0)$ & $14(50.0)$ \\
\hline CHLORAMPHENICOL & $20(71.4)$ & $2(7.1)$ & $6(21.4)$ \\
\hline TETRACYCLINE & $7(25.0)$ & $0(0)$ & $21(75.0)$ \\
\hline CEFTAZIDIME & $0(0)$ & $0(0)$ & $28(100)$ \\
\hline CEFOTAXIME & $1(3.6)$ & $3(10.7)$ & $24(85.7)$ \\
\hline GENTAMICIN & $12(42.9)$ & $2(7.1)$ & $14(50.0)$ \\
\hline CIPROFLOXACIN & $8(28.6)$ & $0(0)$ & $20(71.4)$ \\
\hline OFLOXACIN & $8(28.6)$ & $0(0)$ & $20(71.4)$ \\
\hline AMOXYCILLIN/CLAVULANATE & $27(96.4)$ & $0(0)$ & $1(3.6)$ \\
\hline PENICILLIN G & $20(71.4)$ & $6(21.4)$ & $2(7.1)$ \\
\hline CO-TRIMOXAZOLE & $23(82.1)$ & $4(14.3)$ & $1(3.6)$ \\
\hline
\end{tabular}

$=4.98, \mathrm{p}=0.08)$. Listeria monocytogenes prevalence of $7.0 \%$ was recorded in this study.

Listeria species isolated showed a high level of resistance to the tested antibiotics (Table 2). In general, the listeria species were susceptible to Augmentin 


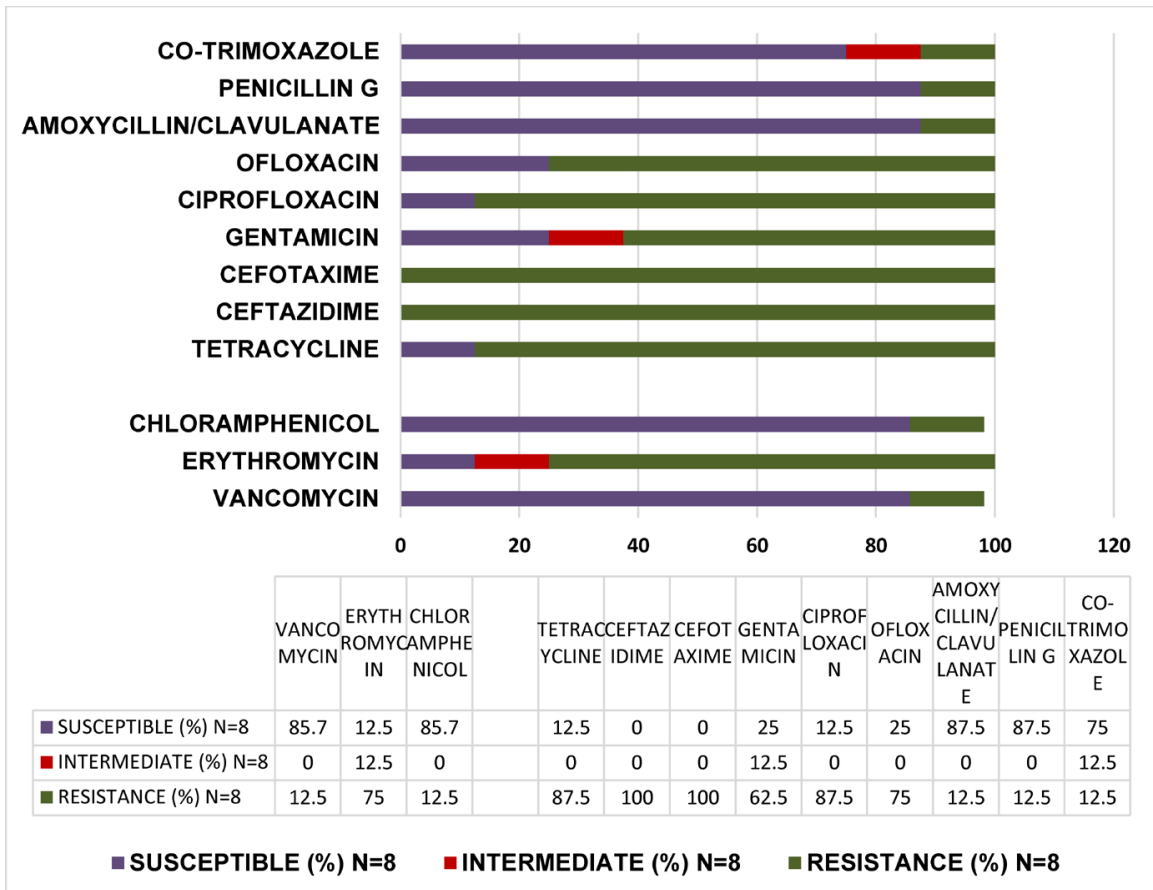

Figure 2. Antibiotic susceptibility pattern of Listeria monocytogen Isolates.

(96.4\%), vancomycin (85.7\%), co-trimoxazole (82.1\%), penicillin G (71.4\%) and chloramphenicol (71.1\%) but resistant to ceftazidime (100\%), cefotaxime (85.7\%), tetracycline (75.0\%), ciprofloxacin (71.4\%), ofloxacin (71.4\%), gentamicin (50\%) and erythromycin (50\%). The study recorded very low susceptibility to the quinolones tested (ciprofloxacin and ofloxacin). A large proportion of the Listeria isolates $(22 / 28(78.6 \%))$ were resistant to 3 or more classes of antibiotics with an average resistance of 4.6 antibiotics classes. Similarly, the Listeria monocytogenes strains were resistant to ceftazidime (100\%), cefuroxime (100\%), ciprofloxacin (87.5\%), tetracycline (87.5\%), ofloxacin (75.0\%), erythromycin (75\%) and gentamycin (62.5\%) Figure 2.

\section{Discussion}

Poultry farming is a common practice in Nigeria, especially in rural areas. Many people raise poultry in large or small scale within their homes and these birds are used to produce eggs or meat, while the manure is used as a supplement or substitute for inorganic fertilizers on Nigerian farms. Four major Listeria species including Listeria ivanovii, L. monocytogenes, L. grayi and L.innocua were identified from rural farms in Lagos State. These key listeria species have also been reported by previous studies as major contaminants of foods sold in different parts of Nigeria [6] [18] [19] [20]. Daniel et al. [4], reported 14.17\% contamination rate for listeria species in commercially frozen and fresh chicken sold within Markurdi metropolis, Nigeria with L. grayi $(58.82 \%)$ standing out as the most occurring species.

Listeria monocytogenes cause a rare but often severe illness known as Listeri- 
osis which is most often characterized by febrile gastroenteritis, sepsis, and meningitis and may result in severe illness or death especially in immunocompromised individuals [21]. The low prevalence of L. monocytogenes (7.0\%) recorded in this study agrees with a study in France where 10.5\% contamination of feacal samples of laying and broiler flocks with L. monocytogenes was reported [10]. However, the findings contrast with a previous study in Oyo State South-Western Nigeria which reported high level (91.5\%) of contamination of chicken flocks and meat with L. monocytogenes [5]. Comparison of prevalence results among different studies can be influenced by variation in sampling strategies and differences in detection methods used. A study in Sokoto Nigeria [22] detected Listeria in 39 out of 192 raw milk samples collected from lactating cows in nomadic herds and small-scale dairy farms. The implicated Listeria species were innocua, L. ivanovii, L. monocytogenes, L. welshimeri and L. selegeri and the authors alluded it to environmental contamination due to unhygienic milking. Another report identified poor methods of pasteurization as a major contributor to high microbial counts in milk [23].

The overall prevalence of listeria species (24.5\%) and Listeria monocytogenes (7.0\%) recorded in our study unveils potential faecal shedding of Listeria species in poultry chicken in rural farms in Lagos State and this could be a likely source of environmental contamination and could ultimately result in transmission of multi-drug resistant Listeria infections to humans. This finding is coming at heels of a recent report of an alarming low level of knowledge of food-borne illness caused by $L$. monocytogenes among pregnant women attending a tertiary healthcare center in Lagos Stats, albeit pregnant women are globally adjudged to be at increased risk of acquiring listeriosis [24]. A study in France investigated 774 poultry samples and concluded that $L$. monocytogenes is prevalent in the production systems of laying hens (15.5\%) and broilers (32\%) [10].

The Listeria species isolated in this study showed a high level of resistance to the tested antibiotics with majority $(78.6 \%)$ of the Listeria isolates resistant to 3 or more classes of antibiotics (Multi-drug resistance). Similar resistance trends have been reported in listeria species isolated from frozen meat [6], chicken and chicken flocks [4] [5] as well as ready-to-eat vegetables and raw milk sold across Nigeria. Studies have observed a pattern of emergence of resistance among strains of Listeria spp isolated from food and domestic animals which are resistant to one or more antibiotics [25] [26]. Although Listeria species showed moderate susceptibility to penicillin which is the drug of choice in the treatment of Listeriosis, resistant to quinolones which are wide spectrum antibiotics used in the treatment of most bacterial infection is a cause for concern. Listeria species can either acquire or transfer antibiotic resistances' genes from plasmid and transposons of other bacterial species either in vivo or in vitro in the intestinal tract [27]. A recent study by Omogbai and Esokpunwu [6] similarly revealed emerging resistancein Listeria species isolated, with most resistant to Ampiclox, Amoxicillin and Septrin. 
Listeria monocytogenes species isolated in this study exhibited high level of antibiotic resistance as well. This is worrisome because Listeriosis caused by L. monocytogenes can have mortality rates as high as $30 \%$, especially among vulnerable groups such as infants, pregnant women and the elderly even without being resistant [28]. Therefore, development of antimicrobial resistance by this group of bacteria could portend a huge public health and economic burden. As a proactive measure, most western countries have taken the initiative to develop policies and guidelines to monitor and control L. monocytogenes in foods as well as educate vulnerable population on the need to avoid high risk foods. Unfortunately, such interventions do not exist in Nigeria and some other African countries. Resistance to the cephalosporins (Ceftazidime 100\% and Cefuroxime $100 \%$ ) recorded in this study is not surprising as Listeria monocytogenes strains have been shown to be intrinsically resistant to broad spectrum cephalosporins [29]. However, resistant to flouroquinolones (ciprofloxacin $87.5 \%$ and ofloxacin 75.0\%) which are broad spectrum antibiotics recorded in this study is a cause for concern and may be attributable to the indiscriminate use and abuse in human and veterinary medicine. The choice drug for treating listeriosis is a $\beta$-lactam (ampicillin or penicillin) alone or combined with an aminoglycoside usually gentamicin [30]. However, the L. monocytogenes strains were moderately susceptible to Augmentin (75.0\%) and Gentamicin (62.5\%). This finding supports a previous study by Ishola et al. [5] who reported $100 \%$ resistance to cefuroxime by the $L$. monocytogenes isolated from chicken and chicken flocks tested while the highest sensitivity (86.1\%) was obtained with amoxicillin clavulanate. In a study on human Listeria monocytogenes strains in Brazil, all strains were susceptible to ampicillin, cephalothin, erythromycin, gentamicin, teicoplanin and vancomycin [31] while only one (1.5\%), and two (3\%) strains showed resistance to rifampin and trimethoprim-sulfamethoxazole respectively [31]. The growing trend of antibiotic resistance among Listeria species may be attributable to indiscriminate use of antibiotics in poultry farming as growth promoters and for treatment of infections [32]. In light of the recent zoonotic outbreak and shift towards a one health paradigm. There is need to urgently address the emergence of resistance through implementation of antibiotic stewardship in veterinary science as well as establish a monitoring trend for the development of antimicrobial resistance among this organism.

One major limitation of the study is that the LGAs were purposively selected and may not be a true representative of the entire rural community in Lagos State. Also, the low sample size used in this study prevents generalization of findings. A further research into the genetic variations of listeria species with reference to resistance/susceptibility to common antibiotics using a larger sample is required for better understanding of the epidemiological trend.

\section{Conclusion}

There was a high occurrence of multi-drug resistant Listeria species in faecal 
sample of poultry chickens in Lagos state which may be an important vector in the contamination of the environment and transmission of antimicrobial resistant Listeria to consumers. Our findings suggest that poultry chicken may represent a potentially important reservoir for multi-drug resistant Listeria species. This underscores the need for implementation of proper hygienic and sanitary measures during slaughtering and evisceration operations to prevent zoonotic transmission of Listeria species through consumption of contaminated chicken meat and eggs by humans.

\section{Author's Contribution}

This work was done in collaboration among all authors. The first author EEC designed the study, wrote the draft manuscript and corresponded with the journal. Authors EEC, VNI and OFD participated in the sample collection and laboratory analysis. Author EEC conducted the data analysis. All authors contributed to the literature searches and approved the final manuscript.

\section{Conflicts of Interest}

The authors declare no conflicts of interest regarding the publication of this paper.

\section{References}

[1] Oliver, S.P., Jayarao, B.M. and Almeida, R.A. (2005) Foodborne Pathogens in Milk and the Dairy Farm Environment: Food Safety and Public Health Implications. Foodborne Pathogens and Disease, 2, 115-129. https://doi.org/10.1089/fpd.2005.2.115

[2] Fenlon, D.R., Wilson, J. and Donachie, W. (1996) The Incidence and Level of Listeria monocytogenes Contamination of Food Sources at Primary Production and Initial Processing. Journal of Applied Bacteriology, 81, 641-650. https://doi.org/10.1111/j.1365-2672.1996.tb03559.x

[3] Wagner, M., Auer, B., Trittremmel, C., Hein, I. and Schoder, D. (2007) Survey on the Listeria Contamination of Ready-to-Eat Food Products and Household Environments in Vienna, Austria. Zoonoses and Public Health, 54, 16-22. https://doi.org/10.1111/j.1863-2378.2007.00982.x

[4] Daniel, S.T., Umeh, E.U. and Iheukwumere, C.C. (2015) Contamination and Antibiotic Susceptibility Profile of Listeria Species in Frozen and Fresh Chicken Sold in Makurdi, Nigeria. International Journal of Current Microbiology and Applied Sciences, 4, 617-623.

[5] Ishola, O.O., Mosugu, J.I. and Adesokan, H.K. (2016) Prevalence and Antibiotic Susceptibility Profiles of Listeria monocytogenes Contamination of Chicken Flocks and Meat in Oyo State, South-Western Nigeria: Public Health Implications. Journal of Preventive Medicine and Hygiene, 57, E157-E163.

[6] Omogbai, B.A. and Esokpunwu, D.E. (2019) Molecular Characterization and Antibiotic Resistance Patterns of Listeria Species in Frozen Beef and Chicken Sold in Benin City, Nigeria. Food and Applied Bioscience Journal, 7, 68-86.

[7] Akpavie, S.O. and Ikheloa, J.O. (1992) An Outbreak of Listeriosis in Cattle in Nigeria. Revue d Elevage et de Medecine Veterinaire des Pays Tropicaux, 45, 263-264. 
https://doi.org/10.19182/remvt.8914

[8] Chukwu, C.O., Muhammad, M.J., Nwankpa, N.D., Chukwu, I.D. and Olabode, A.O. (2006) Listeric Septicaemia and Abotion in African Buffalo (Syncerus caffer). Animal Production Research Advances, 2, 194-196.

https://doi.org/10.4314/apra.v2i4.36339

[9] Oni, O.O., Adesiyun, A.A., Adekeye, J.O. and Sai'du, S.N. (1989) Sero-Prevalence of Agglutinins to Listeria monocytogenes in Nigerian Domestic Animals. Revue d'Elevage et de Medecine Veterinaire des Pays Tropicaux, 42, 383-388.

[10] Chemaly, M., Toquin, M., Le notre, Y. and Fravalo, P. (2008) Prevalence of Listeria monocytogenes in Poultry Production in France. Journal of Food Protection, 71, 1996-2000. https://doi.org/10.4315/0362-028X-71.10.1996

[11] Hitchins, A.D., Jinneman, K. and Chen, Y. (2017) Detection of Listeria monocytogenes in Foods and Environmental Samples, and Enumeration of Listeria monocytogenes in Foods. Bacteriological Analytical Manual (BAM).

https://www.fda.gov/food/laboratory-methods-food/bam-chapter-10-detection-liste ria-monocytogenes-foods-and-environmental-samples-and-enumeration

[12] Curtis, G.D., Mitchell, M.G., King, A.F. and Griffin, E.J. (1989) Differential Medium for the Isolation of Listeria monocytogenes. Letters in Applied Microbiology, 8, 95-98. https://doi.org/10.1111/j.1472-765X.1989.tb00231.x

[13] Rapeanu, G., Parfere, G., Horincar, V., Polcovnicu, C., Ionescu, L. and Barhim, G. (2008) Confirmation and Identification of Listeria Species from Fresh Lettuce. Romanian Biotechnological Letters, 13, 32-36.

[14] Dabrowski, W., Szymanska, L., Koronkiewicz, A. and Medrala, D. (2003) Evaluation of Efficacy of Tests Recommended by PrPN EN ISO 11290-1:1999 Standard for Identification of Listeria spp. and Listeria monocytogenes Isolated from Meat and Meat Processing Environment. Polish Journal of Food and Nutrition Sciences, 12, 51-55.

[15] Sambrook, J., Fritsch, E. and Maniatis, T. (1989) Molecular Cloning: A Laboratory Manual. Second Edition, Cold Spring Harbor Laboratory Press, Cold Spring Harbor, 1e3. https://doi.org/10.1128/JCM.42.8.3819-3822.2004

[16] Doumith, M., Buchrieser, C., Glaser, P., Jacquet, C. and Martin, P. (2004) Differentiation of the Major Listeria monocytogenes Serovars by Multiplex PCR. Journal of Clinical Microbiology, 42, 3819-3822. https://doi.org/10.1128/JCM.42.8.3819-3822.2004

[17] Clinical Laboratory Standard Institute (2015) Performance Standard for Antimicrobial Susceptibility Testing. Twenty Fifth Informational Supplement. M100-S25.

[18] Salihu, M.D., Junaidu, A.U., Manga, S.B., Gulumbe, M.L., Magaji, A.A., Ahmed, A., Adamu, A.Y., Shittu, A. and Balarabe, I. (2008) Occurrence of Listeria monocytogenes in Smoked Fish in Sokoto, Nigeria. African Journal of Biotechnology, 7, 3082-3084.

[19] Ajayeoba, T.A., Atanda, O.O., Obadina, A.O., Bankole, M.O. and Adelowo, O.O. (2016) The Incidence and Distribution of Listeria monocytogenes in Ready-to-Eat Vegetables in South-Western Nigeria. Food Science \& Nutrition, 4, 59-66. https://doi.org/10.1002/fsn3.263

[20] Ezeonu, I.M., Ononugbo, C.M. and Ike, A.C. (2018) Molecular Characterization of Listeria monocytogenes Isolated from a Ready-to-Eat Fermented Milk and Cereal Product, Fura-de-Nunu. African Journal of Microbiology Research, 12, 448-455. https://doi.org/10.5897/AJMR2018.8828

[21] Jackson, K.A., Iwamoto, M. and Swerdlow, D. (2010) Pregnancy-Associated Listeri- 
osis. Epidemiology \& Infection, 138, 1503-1509. https://doi.org/10.1017/S0950268810000294

[22] Yakubu, Y., Salihu, M.D., Faleke, O.O., Abubakar, M.B., Junaidu, A.U., Magaji, A.A., Gulumbe, M.L. and Aliyu, R.M. (2012) Prevalence and Antibiotic Susceptibility of Listeria monocytogenes in Raw Milk from Cattle Herds within Sokoto Metropolis, Nigeria. Sokoto Journal of Veterinary Sciences, 10, 13-17. https://doi.org/10.4314/sokjvs.v10i2.3

[23] Lawan, M.K., Abdulsalawu, F.O., Suleiman, A., Aluwong, T. and Yaqub, L.S. (2012) Microbial Assessments of Bulk Milk before and after Pasteurization in Two Different Dairy Farms in Zaria, Nigeria. International Journal of Dairy Science, 7, 103-108. https://doi.org/10.3923/ijds.2012.103.108

[24] Chukwu, E. and Nwaokorie, F. (2020) Listeriosis Knowledge and Attitude among Pregnant Women Attending a Tertiary Health Institution, South Western Nigeria. Advances in Infectious Diseases, 10, 64-75. https://doi.org/10.4236/aid.2020.102006

[25] Safdara, A. and Armstrong, D. (2003) Antimicrobial Activities against 84 Listeria monocytogenes Isolates from Patients with Systemic Listeriosis at a Comprehensive Cancer Center (1955-1997). Journal of Clinical Microbiology, 41, 483-485. https://doi.org/10.1128/JCM.41.1.483-485.2003

[26] Chukwu, O.C., Ogbonna, C.I., Olabode, A.O., Chukwu, A.I., Onwuliri, F.C. and Nwakiti, O.O. (2006) Listeria monocytogenes in Nigerian Processed Meat and Ready-to-Eat-Dairy Products. Nigerian Journal of Microbiology, 20, 900-904. https://doi.org/10.4314/apra.v2i2.36317

[27] Pourshaban, M., Ferrini, A.M., Cannoni, V., Oliva, B. and Aurelli, P. (2002) Transferable Tetracycline Resistance in Listeria monocytogenes from Food in Italy. Journal of Medical Microbiology, 51, 564-566. https://doi.org/10.1099/0022-1317-51-7-564

[28] Mansouri-Najand, L., Kianpour, M., Sami, M. and Jajarmi, M. (2015) Prevalence of Listeria monocytogenes in Raw Milk in Kerman, Iran. Journal of Veterinary Research, Forum, 6, 223-226.

[29] Krawczyk-Balska, A. and Markiewicz, Z. (2016) The Intrinsic Cephalosporin Resistome of Listeria monocytogenes in the Context of Stress Response, Gene Regulation, Pathogenesis and Therapeutics. Journal of Applied Microbiology, 120, 251-265. https://doi.org/10.1111/jam.12989

[30] Ramaswamy, V., Cresence, V.M., Rejitha, J., Mohandas, U.L., Dharsana, K.S., Suryaprasad, P. and Helan, M.V. (2007) Listeria: Review of Epidemiology and Pathogenesis. Journal of Microbiology, Immunology and Infection, 40, 4-13.

[31] Falavina dos Reis, C.M., Barbosa, A.V., Rusak, L.A., Vallim, D.C. and Hofer, E. (2011) Antimicrobial Susceptibilities of Listeria monocytogenes Human Strains Isolated from 1970 to 2008 in Brazil. Revista da Sociedade Brasileira de Medicina Tropical, 44, 173-176.

[32] Xu, J., Sangthong, R., McNeil, E., Tang, R. and Chongsuvivatwong, V. (2020) Antibiotic Use in Chicken Farms in Northwestern China. Antimicrobial Resistance and Infection Control, 9, 10. https://doi.org/10.1186/s13756-019-0672-6 